Editorial

\title{
'Missing Adenocarcinomas': Are They a Real Problem in Cervical Cancer Screening in Brazil?
}

\author{
Diama Bhadra Vale ${ }^{1}$ Joana Fróes Bragança ${ }^{1}$ Luiz Carlos Zeferino ${ }^{1}$ \\ ${ }^{1}$ Department of Obstetrics and Gynecology, Universidade Estadual de \\ Campinas, Campinas, SP, Brazil
}

Rev Bras Ginecol Obstet 2019;41:579-580.

Screening and human papillomavirus (HPV) vaccine are the most critical strategies for cervical cancer control. ${ }^{1}$ The impact of vaccine programs has not been fully demonstrated yet due to the long natural history of the neoplasia. Regions that have implemented organized screening had efficiently reduced their incidence and mortality rates. Even in Brazil, where screening is opportunist, the cervical cancer rate is going down, dropping to the fourth most common female cancer. $^{2-4}$

The acquired knowledge about the pathogenesis of cervical cancer has proved that HPV DNA test is more efficient than cytology in detecting precursor lesions and reducing the incidence of cervical cancer. In screening programs, the HPV DNA test anticipates the diagnosis with a higher sensitivity. ${ }^{5,6}$ The most robust evidence comes from the systematic review by Ronco et $\mathrm{al}^{6}{ }^{6}$ who analyzed four randomized trials that enrolled 176,464 women aged 20-64 years, who were randomly assigned to the HPV DNA intervention group or the cytology control group. The authors showed a benefit with the HPV DNA test for the detection of invasive squamous cell carcinoma $(0.78,0.49-1.25)$ that was even higher for adenocarcinoma (odds ratio [OR]: $0.31 ; 95 \%$ confidence interval [95\% CI]: 0.14-0.69). ${ }^{6}$

This finding might be related to the limitations of cytology in detecting endocervical lesions: endocervical glands are harder to sample and, given the rarity of these lesions, reading and interpreting abnormal findings is more difficult. ${ }^{7-9}$ Although invasive adenocarcinomas are usually detected in more advanced stages, cytology screening is associated with the downstaging of these lesions. ${ }^{9}$

However, as cervical cancer rates are expected to fall, a new debate emerges regarding cancers not related to HPV infection, like some rare endocervical adenocarcinomas.

Invasive endocervical adenocarcinoma is a difficult histological type for pathologists. Recently, attempts are being made to switch to a different endocervical adenocarcinoma classification that would more precisely reflect the different prognosis observed in the various subtypes. ${ }^{10,11}$ Currently, misclassification is common. One of the proposals is the classification based on the morphologic features linked to HPV: HPV-associated (HPVA) and HPV-unassociated (NHPVA) features. The NHPVA includes such subtypes as endometrioid, gastric, minimal deviation, clear cell, serous and mesonephric tumors, and is related to a worse prognosis than that of the HPVA subtypes. ${ }^{11}$

The pathogenesis of NHPVA subtypes is poorly understood. The minimal deviation and gastric subtypes may share the same precursor lesion, which is called lobular endocervical glandular hyperplasia, and some are associated with PeutzJeghers syndrome. ${ }^{12,13}$ Serous tumors are associated with $p 53$ gene mutations, as serous endometrial adenocarcinoma and endometrioid tumors might represent endometrial cancers in origin that have spread to the cervix. ${ }^{14}$

The positivity of HPV in adenocarcinomas is high, usually around $90 \%$. A recent study by Pirog et $\mathrm{al}^{15}$ has provided comprehensive data on the genotype distribution of 760 adenocarcinomas cases from 38 countries between 1940 and 2009. The overall HPV prevalence was of $62.8 \%$, raising the concern about the possibility of missing almost $1 / 3$ of adenocarcinomas with HPV DNA test screening. Although those cases were reviewed through three-level pathology, the authors considered two main reasons for this low HPV prevalence: aging of the paraffin-embedded tissues (older samples showed lower positivity than recent ones), and differences in regional tissue-fixation protocols within countries. Another relevant result was that HPV-negative samples were more common in older women. It is not clear if HPV could be lost during a slow progression tumor or if it is a non-HPV pathogenesis.

Irrespective of the differences in prevalence rates, HPV detection is harder to be demonstrated due to the relative low viral load in the glandular epithelium. The thin epithelium does not support a productive infection, as it is observed in the squamous epithelium. The HPV life cycle involves the infection of a dividing cell and a reservoir in the basal layer. The ability to drive cancer progression is related to the expression of different proteins that may vary according to the position or level of maturity of the cells. The less dynamic scenario of the

Copyright (c) 2019 by Thieme Revinter Publicações Ltda, Rio de Janeiro, Brazil
Address for correspondence DOI https://doi.org/

Diama Bhadra Vale, MD, PhD, Rua 10.1055/s-0039-1698772.

Albert Sabin $\mathrm{s} / \mathrm{n}^{\circ}, 13083-894$, ISSN 0100-7203.

Cidade Universitária Zeferino Vaz,

Campinas, SP, Brazil

(e-mail:dvale@unicamp.br). 
glandular epithelium and the low number of integrated virus copies observed in glandular lesions are barriers to understand how these precursor lesions develop. ${ }^{15-17}$

Brazil and other Latin-American countries have demonstrated some effect of the cytology opportunist screening in reducing the incidence of cervical cancer in the last few decades. ${ }^{4}$ However, this effect is much more discreet than the one observed in countries that have implemented organized screening, with a high-complexity quality control program and a population-based strategy of invitation (call and recall system). ${ }^{18-20}$ For those countries, the shift to the HPV DNA test will improve the efficiency of the programs, but the impact of the superiority of the HPV DNA test may not result in a significant reduction in rates since they already have reached low incidence rates. For those countries, the question of the 'missing adenocarcinomas' seems to be more relevant, as it may correspond to around $3 \%$ to $4 \%$ of the total of cervical cancers, as claimed by Pirog et al. ${ }^{15}$ Even if this estimation is correct, it should be considered that these rare cancers are challenging to be found through cytology or HPV DNA tests.

In regions with moderate to high incidence of cervical cancer, as in Brazil, this shift to the HPV DNA test may cause a more pronounced impact on decreasing rates, particularly if accompanied by an effort to implement organized screening programs. The question of how to prevent and diagnose rare adenocarcinoma subtypes (or the 'missing adenocarcinomas') is currently not as relevant as the necessity to reduce the incidence of squamous cell cancer, irrespective of the test used. Only in the near future, as the incidence of cervical cancer drops, could the 'missing adenocarcinomas' emerge as a critical problem in the screening program in Brazil.

\section{Conflict of Interests}

The authors have none to declare.

\section{References}

1 World Health Organization. Comprehensive cervical cancer control: a guide to essential practice. $2^{\text {nd }}$ ed. Geneva: WHO; 2014

2 Arbyn M, Raifu AO, Weiderpass E, Bray F, Anttila A. Trends of cervical cancer mortality in the member states of the European Union. Eur J Cancer 2009;45(15):2640-2648. Doi: 10.1016/j.ejca.2009.07.018

3 Ministério da Saúde. Instituto Nacional de Câncer José Alencar Gomes da Silva. Estimativa 2018: Incidência de Câncer no Brasil. Rio de Janeiro, RJ: INCA; 2017https://www.inca.gov.br/sites/ufu. sti.inca.local/files//media/document//estimativa-incidencia-decancer-no-brasil-2018.pdf. Accessed July 12, 2018.

4 Vaccarella S, Laversanne M, Ferlay J, Bray F. Cervical cancer in Africa, Latin America and the Caribbean and Asia: Regional inequalities and changing trends. Int J Cancer 2017;141(10): 1997-2001. Doi: 10.1002/ijc.30901

5 Koliopoulos G, Nyaga VN, Santesso N, et al. Cytology versus HPV testing for cervical cancer screening in the general population. Cochrane Database Syst Rev 2017;8:CD008587. Doi: 10.1002/146 51858.CD008587.pub2
6 Ronco G, Dillner J, Elfström KM, et al; International HPV screening working group. Efficacy of HPV-based screening for prevention of invasive cervical cancer: follow-up of four European randomised controlled trials. Lancet 2014;383(9916):524-532. Doi: 10.1016/ S0140-6736(13)62218-7

7 Zappa M, Visioli CB, Ciatto S, Iossa A, Paci E, Sasieni P. Lower protection of cytological screening for adenocarcinomas and shorter protection for younger women: the results of a casecontrol study in Florence. Br J Cancer 2004;90(09):1784-1786. Doi: $10.1038 /$ sj.bjc.6601754

8 Mitchell H, Hocking J, Saville M. Improvement in protection against adenocarcinoma of the cervix resulting from participation in cervical screening. Cancer 2003;99(06):336-341. Doi: 10.1002/cncr.11835

9 Castanon A, Landy R, Sasieni PD. Is cervical screening preventing adenocarcinoma and adenosquamous carcinoma of the cervix? Int J Cancer 2016;139(05):1040-1045. Doi: 10.1002/ijc.30152

10 Roma AA, Fadare O. The pattern is the issue: recent advances in adenocarcinoma of the uterine cervix. Virchows Arch 2018;472 (06):897-905. Doi: 10.1007/s00428-018-2312-6

11 Stolnicu S, Hoang L, Chiu D, et al. Clinical outcomes of HPVassociated and unassociated endocervical adenocarcinomas categorized by the International Endocervical Adenocarcinoma Criteria and Classification (IECC). Am J Surg Pathol 2019;43(04):466-474. Doi: 10.1097/PAS.0000000000001224

12 Mikami Y, Kiyokawa T, Hata S, et al. Gastrointestinal immunophenotype in adenocarcinomas of the uterine cervix and related glandular lesions: a possible link between lobular endocervical glandular hyperplasia/pyloric gland metaplasia and 'adenoma malignum'. Mod Pathol 2004;17(08):962-972. Doi: 10.1038/ modpathol.3800148

13 Kuragaki C, Enomoto T, Ueno Y, et al. Mutations in the STK11 gene characterize minimal deviation adenocarcinoma of the uterine cervix. Lab Invest 2003;83(01):35-45

14 Nofech-Mozes S, Khalifa MM, Ismiil N, et al. Detection of HPVDNA by a PCR-based method in formalin-fixed, paraffin-embedded tissue from rare endocervical carcinoma types. Appl Immunohistochem Mol Morphol 2010;18(01):80-85. Doi: 10.1097/ PAI.0b013e3181ae7240

15 Pirog EC, Lloveras B, Molijn A, et al; RIS HPV TT study group. HPV prevalence and genotypes in different histological subtypes of cervical adenocarcinoma, a worldwide analysis of 760 cases. Mod Pathol 2014;27(12):1559-1567. Doi: 10.1038/modpathol.2014.55

16 Cooper K, Herrington CS, Lo ES, Evans MF, McGee JO. Integration of human papillomavirus types 16 and 18 in cervical adenocarcinoma. J Clin Pathol 1992;45(05):382-384. Doi: 10.1136/jcp.45.5.382

17 Schiffman M, Doorbar J, Wentzensen N, et al. Carcinogenic human papillomavirus infection. Nat Rev Dis Primers 2016;2:16086. Doi: 10.1038/nrdp.2016.86

18 Vaccarella S, Lortet-Tieulent J, Plummer M, Franceschi S, Bray F. Worldwide trends in cervical cancer incidence: impact of screening against changes in disease risk factors. Eur J Cancer 2013;49 (15):3262-3273. Doi: 10.1016/j.ejca.2013.04.024

19 Basu P, Ponti A, Anttila A, et al. Status of implementation and organization of cancer screening in The European Union Member States-Summary results from the second European screening report. Int J Cancer 2018;142(01):44-56. Doi: 10.1002/ ijc.31043

20 Basu P, Mittal S, Bhadra Vale D, Chami Kharaji Y. Secondary prevention of cervical cancer. Best Pract Res Clin Obstet Gynaecol 2018;47:73-85. Doi: 10.1016/j.bpobgyn.2017.08.012 